\title{
PEMBELAJARAN MODEL COGNITIVE GROWTH BERBASIS SCIENTIFIC APPROACH UNTUK MENINGKATKAN AKTIVITAS DAN KEMAMPUAN BERPIKIR KRITIS
}

\author{
Aprilia Nurul Chasanah ${ }^{\bowtie}$
}

Prodi Pendidikan Matematika, Universitas Tidar

\begin{abstract}
Info Artikel Abstract
Sejarah Artikel:

Diterima 12 Feb 2019

Direvisi 22 Mei 2019

Disetujui $25 \mathrm{Mei}$

2019

Keywords:

Activities, Critical

Thinking, Cognitive

Growth, Scientific

Approach

A person's critical thinking ability in a study field cannot be separated from his understanding on the materials being studied. Therefore, in order that the students are able to think critically in Mathematics, they must understand it well. The purpose of this study is to improve the students' critical thinking and activities in the Mathematics learning using Scientific Approach-based Cognitive Growth model. This is a Classroom Action Research (CAR) study conducted at SMP IT Ihsanul Fikri, Magelang city on the VIIIB class students in the Mathematics subject. The instruments used are observation sheets of student activities, critical thinking skills test sheets, and observation sheets for the implementation of the learning. The percentage of the improvement on the students' critical thinking in cycle $I=57,58 \%$, cycle $I I=67,24 \%$, and cycle $I I I=89,01 \%$. The percentage of the students' activities in cycle $I=39,20 \%$, cycle $I I=59,40 \%$, and cycle $I I I=93,93 \%$. It can be concluded that the application of Scientific Approach-based Cognitive Growth model in the learning process can improve the activities and critical thinking ability of VIII grade students in the subject mattertopics of cubes and beams at the SMP IT Ihsanul Fikri of Magelang city.
\end{abstract}

Paper type:

Research paper

\begin{abstract}
Abstrak
Kemampuan berpikir kritis seseorang dalam suatu bidang studi tidak dapat terlepas dari pemahamannya terhadap materi bidang studi tersebut. Dengan demikian agar siswa dapat berpikir kritis dalam matematika, maka siswa harus memahami matematika dengan baik. Tujuan penelitian ini adalah meningkatkan aktivitas dan kemampuan berpikir kritis siswa pada pembelajaran matematika dengan model Cognitive Growth berbasis Scientific Approach. Penelitian ini merupakan Penelitian Tindakan Kelas (PTK) yang dilaksanakan di SMP IT Ihsanul Fikri Kota Magelang pada kelas VIIIB mata pelajaran Matematika. Instrumen yang digunakan yaitu lembar pengamatan aktivitas siswa, lembar tes kemampuan berpikir kritis, dan lembar observasi pelaksanaan pembelajaran. Presentase peningkatan berpikir kritis siswa pada siklus I $=57,58 \%$, siklus II $=67,24 \%$, dan siklus III $=89,01 \%$. Presentase untuk aspek aktivitas siswa pada siklus I= $39,20 \%$, siklus $\mathrm{II}=59,40 \%$, dan siklus III $=$ 93,93\%. Dapat disimpulkan bahwa penerapan pembelajaran dengan model Cognitive Growth berbasis Scientific Approach dapat meningkatkan aktivitas dan kemampuan berpikir kritis siswa kelas VIII pada materi pokok kubus dan balok di SMP IT Ihsanul Fikri Kota Magelang.
\end{abstract}

(C) 2019 Universitas Muria Kudus

\begin{tabular}{lc}
\hline Alamat korespondensi: & p-ISSN 2615-4196 \\
Program Studi Pendidikan Matematika, Universitas Muria Kudus & e-ISSN 2615-4072 \\
Kampus UMK Gondangmanis, Bae Kudus Gd. L. 1t I PO. BOX 53 Kudus &
\end{tabular}

Tlp (0291) 438229 ex.175 Fax. (0291) 437198

E-mail: aprilianurul@untidar.ac.id 


\section{PENDAHULUAN}

Salah satu tujuan diberikannya matematika di jenjang pendidikan dasar dan menengah, yaitu untuk "mengembangkan potensi peserta didik agar menjadi manusia yang beriman dan bertakwa kepada Tuhan Yang Maha Esa, berakhlak mulia, sehat, berilmu, cakap, kreatif, mandiri, dan menjadi warga negara yang demokratis serta bertanggung jawab" (BSNP, 2006). Selain itu juga diharapkan agar siswa dapat menggunakan matematika sebagai cara bernalar (berpikir logis, kritis, sistematis, dan objektif). Menurut Gagne (dalam Ruseffendi, 2008) bahwa objek tidak langsung dari mempelajari matematika adalah agar siswa memiliki kemampuan memecahkan masalah. Berdasarkan pendapat Gagne dan tujuan Kurikulum Matematika, dapat ditarik kesimpulan bahwa untuk dapat memecahkan suatu masalah, para siswa perlu memiliki kemampuan bernalar yang dapat diperoleh melalui pembelajaran matematika.

Kemampuan bernalar tidak terpisahkan dari kemampuan berpikir kritis. Dengan kata lain kemampuan berpikir kritis merupakan bagian dari penalaran. Hal ini sejalan dengan pendapat Krulik dan Rudnick (1995) bahwa penalaran mencakup berpikir dasar (basic thinking), berpikir kritis (critical thinking), dan berpikir kreatif (creative thinking).

Berpikir kritis merupakan salah satu tahapan berpikir tingkat tinggi. Costa (Liliasari, 2000) mengkategorikan proses berpikir kompleks atau berpikir tingkat tinggi ke dalam empat kelompok yang meliputi pemecahan masalah (problem solving), pengambilan keputusan (decision making), berpikir kritis (critical thinking), dan berpikir kreatif (creative thinking).

Kemampuan berpikir kritis seseorang dalam suatu bidang studi tidak dapat terlepas dari pemahamannya terhadap materi bidang studi tersebut. Dengan demikian agar siswa dapat berpikir kritis dalam matematika, maka siswa harus memahami matematika dengan baik. Siswa dapat mengembangkan kemampuan berpikir kritis ketika menghadapi masalah matematika, mengidentifikasi solusi yang mungkin, dan mengevaluasi hasil (Su, H.F, et all, 2016).

Berdasarkan uraian sebelumnya tampak bahwa berpikir kritis berkaitan erat dengan argumen, karena argumen sendiri adalah serangkaian pernyataan yang mengandung pernyataan penarikan kesimpulan. Seperti diketahui kesimpulan biasanya ditarik berdasarkan pernyataan-pernyataan yang diberikan sebelumnya atau yang disebut premis.
Berdasarkan argumen yang valid sebuah kesimpulan harus ditarik secara logis dari premispremis yang ada. Hal ini sesuai dengan pendapat Ennis (2001) yang secara singkatnya menyatakan bahwa terdapat enam unsur dasar dalam berpikir kritis, yaitu fokus (focus), bernalar (reason), kesimpulan (inference), situasi (situation), kejelasan (clarity), dan tinjauan ulang (overview).

Selain rumusan indikator berpikir kritis yang dikemukakan oleh Ennis, terdapat pula rumusan indikator lain yang dikemukakan oleh Henri Clucow, Brace Govan, Garrison, Anderson, Archer, Newman, Webb, Cochrane, dan Bullen (Perkins, 2006). Meskipun rumusan tersebut memiliki perbedaan sesuai dengan sudut pandang, akan tetapi para ahli tersebut memiliki konsensus mengenai indikator keterampilan berpikir kritis (Facione, 1995). Berdasarkan konsensus tersebut, para ahli menyebutkan enam ketrampilan kognitif dalam berpikir kritis, antara lain: interpretasi, analisis, evaluasi, inferensi, eksplanasi, dan pengaturan diri (Facione,1995).

Untuk menilai kemampuan berpikir kritis Watson dan Glaser (1980) melakukan pengukuran melalui tes yang mencakup lima buah indikator, yaitu mengenal asumsi, melakukan inferensi, deduksi, interpretasi, dan mengevaluasi argumen. Berdasarkan kemampuan yang berkaitan dengan berpikir kritis yang dikemukakan oleh para ahli, ternyata pengukuran kemampuan berpikir kritis itu sudah tercakup dalam lima buah indikator seperti yang dikemukakan oleh Watson dan Glaser.

Materi yang akan dikembangkan dalam penelitian ini sesuai dengan kebutuhan sekolah yaitu materi geometri khususnya bangun ruang sisi datar. Materi tersebut membutuhkan penangkapan image (bayangan dalam pikiran) dalam bentuk seutuhnya meskipun materi itu tidak disajikan secara utuh. Materi geometri juga merupakan materi yang memerlukan kemampuan dalam membayangkan dan menginterprestasikan sesuatu yang masih abstrak ke dalam gambar di dalam pikiran, sehingga menyulitkan siswa dalam belajar (Nurafni, 2018). Apalagi siswa dalam proses pembelajarannya terkadang kesulitan mengingat apa yang telah dipelajari. Oleh karena itu, sumber belajar yang digunakan oleh siswa dalam pembelajaran pada materi tersebut hendaknya berupa sumber belajar yang dapat memperjelas konsep tersebut sekaligus yang dapat menimbulkan ketertarikan siswa untuk belajar sehingga proses belajar dapat berlangsung optimal.

Kondisi awal sebelum penelitian dilakukan, aktivitas dan kemampuan berpikir 
kritis matematika kelas VIII B SMP IT Ihsanul Fikri Kota Magelang pada semester 2 tahun pelajaran 2017/2018 masih rendah. Bukti aktivitas belajar masih rendah dapat dilihat oleh peneliti pada saat peneliti melakukan pembelajaran pada kondisi awal. Pembelajaran yang dilakukan sebanyak 3 kali tatap muka pada kondisi awal dari 25 siswa di kelas VIII B ternyata yang berani bertanya hanya 5 anak. Sedangkan peneliti memberikan pertanyaan kepada siswa yang berani tunjuk jari selama 3 tatap muka hanya 3 anak. Pada saat pembelajaran dari 25 anak ternyata yang mengantuk ada 6 anak. Pada saat pemberian tugas yang mengerjakan sungguh-sungguh ada 13 anak. Selain itu, saat diberi soal berbeda ternyata ada 3 anak yang bisa menjawab.

Sedangkan kemampuan berpikir kritis matematika rendah dapat dilihat peneliti dari nilai ulangan harian setelah pembelajaran kondisi awal selesai. Dari 25 siswa yang mengikuti ternyata nilai tertinggi 65 nilai terendah 32. Sebagian besar nilai siswa berkisar 57, nilai modus 56, median 59 dan nilai rata-ratanya 61. Padahal Kriteria Ketuntasan Minimal (KKM) telah ditetapkan sekolah sebesar 75. Kemampuan berpikir kritis matematika siswa kelas VIIIB rendah kemungkinan disebabkan oleh kondisi awal peneliti dalam mengajar belum menggunakan model pembelajaran yang sesuai dan perangkat yang mendukung dalam pembelajaran.

Model Cognitive Growth merupakan salah satu pembelajaran yang dapat meningkatkan kemampuan berpikir kritis. Adapun sintaks pembelajaran cognitive growth sebagai berikut.

Tabel 1. Sintaks Model Cognitive Growth

\begin{tabular}{|c|c|}
\hline Fase & Deskripsi \\
\hline $\begin{array}{c}\text { Fase } 1 \\
\text { Confrontation } \\
\text { with stage- } \\
\text { relevant tasks }\end{array}$ & $\begin{array}{llr}\text { Penyatuan tugas/masalah } & \text { sesuai } \\
\text { tahapan, orientasi siswa } & \text { pada } \\
\text { masalah yang akan dipelajari. } & \end{array}$ \\
\hline Fase 2 Inquiry & \begin{tabular}{lr} 
Mengorganisasi & \multicolumn{2}{c}{ siswa untuk } \\
menimbulkan kepekaan siswa dan \\
peningkatan kemampuan berpikir \\
kritis siswa. Menganalisis dan \\
mengevaluasi proses. Proses \\
pembelajaran yang r sudah \\
dilaksanakan dievaluasi/ & direfleksi \\
untuk peningkatan & kegiatan \\
pembelajaran. Sedangkan hasilnya \\
dikritisi dan dibahas dalam suatu \\
kelas.
\end{tabular} \\
\hline $\begin{array}{c}\text { Fase } 3 \text { Transfer } \\
\text { Phase }\end{array}$ & $\begin{array}{l}\text { Penyatuan tugas/masalah } \\
\text { tahapan, orientasi siswai } \\
\text { masalah. }\end{array}$ \\
\hline
\end{tabular}

Menurut Piaget dalam (Joyce,1992) model Cognitive Growth dalam pembelajaran lebih ditujukan dalam meningkatkan kemampuan berpikir (kognitif). Oleh karena itu, model Cognitive Growth cocok dengan tahap perkembangan pembelajaran dan meningkatkan kemampuan berpikir kritis siswa.

Scientific Mathematic merupakan proyek Eropa yang melibatkkan kerjasama interdisiplinary antara matematika dan ilmu pengetahuan. Hal ini bertujuan untuk mengembangkan pembelajaran ke arah belajar yang komprehensif dan multidimensional mengenai isi dan konsep matematika. Ide dasarnya adalah untuk mendorong pembelajaran matematika dalam konteks ilmiah dan kegiatan siswa (Beckmann, 2009). Kemudian disebutkan bahwa pendekatan ini mengaitkan antara matematika dengan ilmu pengetahuan, sehingga siswa akan mempelajari matematika dengan cara yang menarik. Belajar dengan berkegiatan akan berkontribusi terhadap pemahaman intuitif matematika siswa. Dengan kata lain, belajar matematika yang baik adalah mengalami atau berkegiatan. Pada pembelajaran matematika, langkah - langkah pendekatan scientific ini terdiri dari pengumpulan data dari percobaan, pengembangan dan peyelidikan suatu model matematika dalam bentuk representasi yang berbeda, dan refleksi (Beckmann, 2009).

Berdasarkan Permendikbud No.65 tahun 2013 tentang Standar Proses Pendidikan Dasar dan Menengah telah mengisyaratkan tentang perlunya proses pembelajaran yang dipadu dengan kaidah-kaidah scientific approach/ pendekatan saintifik (Kemendikbud, 2013). Pendekatan scientific pada kurikulum 2013 yang diterapkan di Indonesia menjabarkan langkahlangkah pembelajaran tersebut menjadi lima, yaitu: mengamati, menanya, menalar, mencoba, dan mengkomunikasikan (Kemendikbud, 2013). Oleh karena itu untuk menambah kekhasan kurikulum 2013 maka model Cognitive Growth berbasis scientific approach akan menjadi kekuatan tersendiri dari keberadaan kurikulum 2013 dalam mendukung peningkatan kemampuan berpikir kritis siswa.

\section{METODE PENELITIAN}

Penelitian ini merupakan Penelitian Tindakan Kelas (PTK) yang dilaksanakan selama 4 minggu, pada semester Gasal 2017/2018 bulan Maret 2017. Subjek dari penelitian ini adalah siswa kelas VIII B SMP IT Ihsanul Fikri Kota Magelang, yang berjumlah 25 siswa. Instrumen 
yang digunakan yaitu lembar angket aktivitas siswa, lembar tes kemampuan berpikir kritis, dan lembar observasi pelaksanaan pembelajaran. Adapun tahapan penelitian meliputi perencanaan, pelaksanaan tindakan, observasi, refleksi dan revisi. Secara terperinci pelaksanaan penelitian tindakan kelas dapat dilihat pada Tabel 2.

Tabel 2. Kegiatan Tiap Siklus

\begin{tabular}{|c|c|c|}
\hline No & Tahapan & Kegiatan \\
\hline 1. & Siklus I & $\begin{array}{ll}\text { - } & \text { Identifikasi masalah } \\
\text { - } & \text { Perencanaan I } \\
\text { - } & \text { Pelaksanaan } \\
& \text { Pembelajaran dengan } \\
& \text { Model Cognitive Growth } \\
& \text { dan Observasi } \\
\text { - } & \text { Refleksi }\end{array}$ \\
\hline 2. & Siklus II & $\begin{array}{ll}\text { - } & \text { Perencanaan II (Hasil } \\
& \text { refleksi Siklus I) } \\
\text { - } & \text { Pelaksanaan } \\
& \text { Pembelajaran dengan } \\
& \text { Model Cognitive Growth } \\
& \text { dan Observasi } \\
\text { - } & \text { Refleksi }\end{array}$ \\
\hline 3. & Siklus III & $\begin{array}{l}\text { - Perencanaan III (Hasil } \\
\text { refleksi Siklus II) } \\
\text { - Pelaksanaan } \\
\text { pembelajaran dengan } \\
\text { Model Cognitive Growth } \\
\text { dan Observasi } \\
\text { - } \\
\text { Refleksi }\end{array}$ \\
\hline
\end{tabular}

Data hasil pengamatan aktivitas siswa terdiri dari 20 item dengan memberikan penilaian dalam skala nilai dan kategori penilaian sebagai berikut: tidak setuju $=1$, ragu $=2$, setuju $=3$, dan sangat setuju=4. Selanjutnya rata-rata dikelompokkan berdasarkan interval kategori penilaian sebagai berikut: rendah $=1-20$, sedang $=$ 21-40, tinggi $=41-60$, dan sangat tinggi $=61-80$.

Tes Kemampuan Berpikir Kritis (TKBK) digunakan untuk mengetahui tingkat kemampuan berpikir kritis siswa yang mengukur aspek kelancaran, aspek keluwesan, aspek keaslian, dan aspek elaborasi. Tes ini diberikan kepada siswa sesudah pembelajaran dengan model Cognitive Growth berbasis Scientific Approach. Instrumen ini telah divalidasi oleh validator dan dinyatakan valid.

\section{HASIL DAN PEMBAHASAN}

Hasil yang diperoleh dalam penelitian ini berupa aktivitas dan kemampuan berpikir kritis siswa. Secara terperinci dapat dijelaskan sebagai berikut.

Aktivitas siswa diperoleh dengan menggunakan lembar pengamatan aktivitas siswa yang terdiri dari soal yang memuat indikatorindikator aktivitas siswa. Hasil aktivitas siswa mulai dari siklus I, siklus II, dan siklus III dapat dilihat pada Tabel 3 dan Gambar 1 .

Tabel 3. Rekapitulasi Skor Aktivitas Siswa

\begin{tabular}{lccc}
\hline $\begin{array}{l}\text { Indikator } \\
\text { Aktivitas } \\
\text { Siswa }\end{array}$ & $\begin{array}{c}\text { SIKLUS } \\
\text { I }\end{array}$ & $\begin{array}{c}\text { SIKLUS } \\
\text { II }\end{array}$ & $\begin{array}{c}\text { SIKLUS } \\
\text { III }\end{array}$ \\
\hline Keberanian & 39,00 & 63,00 & 93,00 \\
Motivasi & 40,00 & 63,00 & 88,00 \\
Kerja sama & 43,00 & 68,00 & 81,00 \\
Kreativitas & 35,00 & 63,00 & 97,00 \\
Interaksi & 39,00 & 40,00 & 95,00 \\
Presentase & $39,20 \%$ & $59,40 \%$ & $90,80 \%$ \\
\hline
\end{tabular}

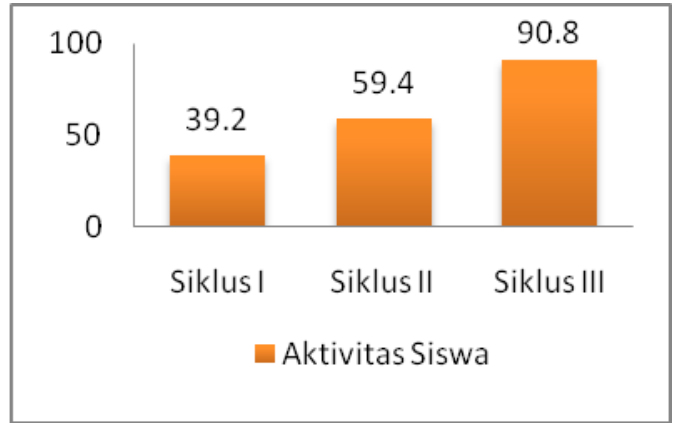

Gambar 1. Hasil Aktivitas Siswa

Berdasarkan Gambar 2 menunjukkan bahwa terjadi peningkatan yang terlihat dari nilai rata-rata siklus I, siklus II, dan siklus III. Hasil rata-rata siklus I aktivitas siswa sebesar 39,2 dengan kategori kurang, hasil rata-rata siklus II sebesar 59,4 dengan kategori kurang, dan hasil rata-rata siklus III sebesar 90,8 dengan kategori tinggi.

Peningkatan aktivitas siswa juga terlihat dari hasil observasi yang menunjukkan kegiatan siswa terlihat sangat tertarik dan antusias pada pembelajaran yang disampaikan oleh guru dan keberanian untuk bertanya dan menjawab pertanyaan, serta lebih interaktif. Hal tersebut seperti pendapat Noviarny (2018) bahwa guru yang mempunyai keterampilan mengajar yang baik akan berdampak pada aktivitas belajar siswa yang juga baik dalam kemampuan komunikasi matematika. Hal ini senada juga dengan Tarigan (2014) yang menjelaskan bahwa penggunaan model pembelajaran dapat meningkatkan aktivitas belajar siswa. Peningkatan aktivitas per aspek aktivitas yang terdiri dari aspek keberanian, 
motivasi, kerja sama, kreativitas, interaksi dapat dilihat pada Gambar 2.

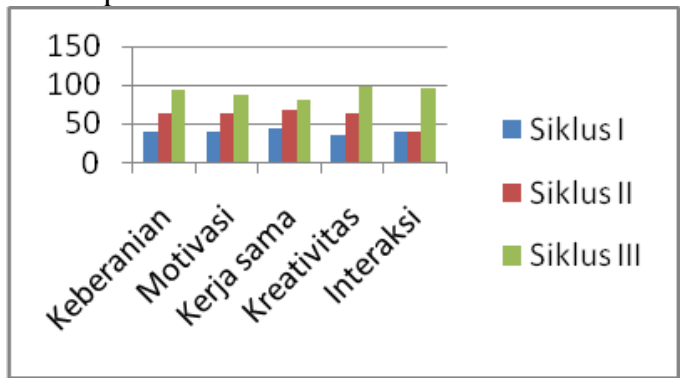

Gambar 2. Hasil Penelitian ditinjau dari Aspek Aktivitas Siswa

Berdasarkan hasil pada Tabel 1 dan Gambar 1 dapat diperoleh bahwa melalui pembelajaran model Cognitive Growth berbasis Scientific Approach dapat meningkatkan aktivitas siswa kelas VIII B SMP IT Ihsanul Fikri Kota Magelang.

Kemampuan berpikir kritis siswa diperoleh dengan menggunakan lembar Tes Kemampuan Berpikir Kritis (TKBK) yang memuat aspek-aspek indikator berpikir kritis. Tes Kemampuan Berpikir Kritis siswa pada materi kubus dan balok dapat dilihat pada Tabel 4.

Tabel 4. Rekapitulasi Nilai Tes Kemampuan

Berpikir Kritis (TKBK) Siswa

\begin{tabular}{|c|c|c|c|}
\hline $\begin{array}{ll}\text { Aspek yang } \\
\text { dinilai }\end{array}$ & $\begin{array}{c}\text { SIKLUS } \\
\text { I }\end{array}$ & $\begin{array}{c}\text { SIKLUS } \\
\text { II }\end{array}$ & $\begin{array}{c}\text { SIKLUS } \\
\text { III }\end{array}$ \\
\hline $\begin{array}{l}\text { Nilai Rata- } \\
\text { rata }\end{array}$ & 70,39 & 76,54 & 81,00 \\
\hline $\begin{array}{l}\text { Nilai } \\
\text { Terendah }\end{array}$ & 52,00 & 70,00 & 77,00 \\
\hline $\begin{array}{l}\text { Nilai } \\
\text { Tertinggi }\end{array}$ & 94,00 & 82,00 & 100,00 \\
\hline $\begin{array}{l}\text { Persentase } \\
\text { Kelulusan }\end{array}$ & $57,58 \%$ & $67,24 \%$ & $89,01 \%$ \\
\hline
\end{tabular}

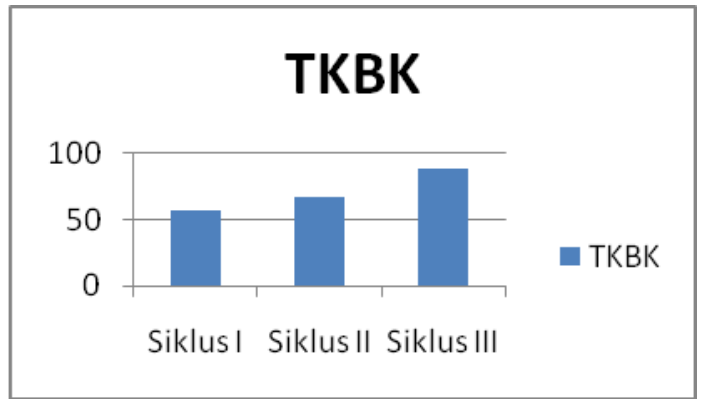

Gambar 3. Hasil Tes Kemampuan Berpikir Kritis (TKBK)

Pada akhir siklus I diberikan soal evaluasi untuk mengukur kemampuan berpikir kritis siswa. Setelah dilakukan analisis data hasil evaluasi siklus I dengan submateri pokok unsur- unsur kubus dan balok diperoleh nilai rata-rata siswa sebesar 70,39, ketuntasan siswa $57,58 \%$ dengan nilai terendah 52 dan nilai tertinggi 94 . Aktivitas siswa pada siklus I pun masih rendah. Hal ini terlihat dari perolehan persentase ratarata sebesar 39,20\%. Berdasarkan data tersebut menunjukkan bahwa pada siklus I belum memenuhi indikator yang telah ditetapkan sehingga harus dilaksanakan siklus berikutnya.

Berdasarkan refleksi pada siklus II menunjukkan peningkatan yang cukup baik. Setelah dilakukan analisis data hasil evaluasi siklus II dengan submateri luas permukaan balok diperoleh nilai rata-rata siswa sebesar 76,54, ketuntasan siswa mencapai $67,24 \%$, nilai terendah 70 dan nilai tertinggi 82. Aktivitas siswa pada siklus II pun lebih baik. Hal ini terlihat dari perolehan persentase rata-rata sebesar 59,40\% hal ini merupakan peningkatan yang cukup signifikan dari siklus I yang mencapai 39,20\%.

Presentase peningkatan berpikir kritis siswa pada siklus siklus $\mathrm{I}=57,58 \%$, siklus $\mathrm{II}=$ $67,24 \%$ dan siklus III $=89,01 \%$. Presentase untuk aspek aktivitas siswa pada siklus $\mathrm{I}=39,20 \%$, siklus II $=59,40 \%$ dan siklus III $=90,80 \%$. Berdasarkan hasil analisis data tentang aktivitas dan kemampuan berpikir kritis siswa melalui model Cognitive Growth berbasis Scientific Approach, efektif diterapkan di kelas VIII B SMP IT Ihsanul Fikri Kota Magelang pada pembelajaran materi kubus dan balok.

\section{SIMPULAN}

Berdasarkan hasil penelitian dan pembahasan maka dapat disimpulkan bahwa model Cognitive Growth berbasis Scientific Approach dapat meningkatkan berpikir kritis matematika dan aktivitas siswa kelas VIII SMP IT Ihsanul Fikri Kota Magelang.

\section{UCAPAN TERIMA KASIH}

Penulis mengucapkan terima kasih kepada segenap tim Pengelola Jurnal Anargya yang telah memberikan kesempatan kepada penulis untuk memublikasikan karya ilmiahnya.

\section{DAFTAR PUSTAKA}

Beckmann, A. 2009. The ScienceMath Project. Germany: The ScienceMath-Group.

BSNP (Badan Standar Nasional Pendidikan). 2006. Standar Isi. Jakarta: BSNP. 
Ennis, R. H. 2001. Critical Thinking Assesment. NJ: Prentice Hall.

Facione, P.A. 2009. Critical Thinking. What It is and Why It Counts Insight Assessment,(Online), (http://www.insightassessment.com, diakses 20 Oktober 2018).

Joyce, B dan Weil, M. 1992. Models of Teaching. Fourth Edition. London: Allyn and Bacon.

Kemdikbud. 2013. Kompetensi Dasar Matematika SMP/MTs. Jakarta: Kemdikbud.

2013. Pendekatan Scientific (Ilmiah) dalam Pembelajaran. Jakarta: Pusbangprodik.

Krulik, S dan Rudnick, J.A. 1995. The New Sourcebook for Teaching Reasoning and Problem Solving in Elementary School. Massachusetts: Allyn \& Bacon A Simon $\&$ Schuster Company.

Liliasari. 2000. Model Pembelajaran untuk Meningkatkan Keterampilan Berpikir Konseptual Tingkat Tinggi Calon Guru IPA. Dalam Proceeding Nasional Science Education Seminar, The Problem of Mathematics and Science Education and Alternative to Solve the Problems. Malang: JICA-IMSTEP FMIPA UM.

Nurafni, et all. 2018. Development of geometry materials based on scientific approach for junior high school students. Journal of Physics: Conf. Series, 948 012002, 14.

Noviarny, D.A., Murtono, \& Ulya,H. 2018. Model Think Talk Write Berbantuan Media Monomat Meningkatkan Kemampuan Komunikasi Matematika Siswa Sekolah Dasar. Jurnal Ilmiah Pendidikan Matematika: ANARGYA, 1(1), 21-28.

Perkins. 2006. Identifying and measuring individual engagement in critical thinking in online discussions: An exploratory case study. An exploratory case study. Educational Technology \& Society, 9 (1), 298-307.

Ruseffendi, E. T. 2008. Pengantar kepada Membantu Guru Mengembangkan Kompetensinya dalam Pengajaran Matematika untuk Meningkatkan CBSA. Bandung: Tarsito.

Su, H.F., Ricci, F.A., \& Mnatsakanian, M. 2016. Mathematical teaching strategies: Pathways to critical thingking and metacognition. Journal of Research in Education and Science (IJRES), 2(1), $190-200$.

Tarigan, D. 2014. Meningkatkan Aktivitas Belajar Siswa dengan Menggunakan Model Make a Match pada Mata Pelajaran Matematika di Kelas V SDN 050687 Sawit Seberang. Jurnal Kreano, 5(1), 56-62.

Watson, G dan Glaser, E. M. 1980. Critical Thinking Appraisal. New York: Harcourt Brace Jovanovich, Inc. 